\title{
CHAPTER THREE SEXUAL DIMORPHISM IN FOSSIL HOMINIDS AND ITS SOCIOECOLOGICAL IMPLICATIONS
}

\author{
HENRY M.MCHENRY
}

\begin{abstract}
'The law of battle for the possession of the females appears to prevail throughout the whole great class of mammals', wrote Darwin (1892:552). 'Most naturalists will admit that the greater size, strength, courage, and pugnacity of the male, his special weapons of offence, as well as his special means of defence, have been acquired or modified through that form of selection which I have called sexual.' These are prophetic words in the sense that after more than a century of study, most naturalists do accept sexual selection as the cause of sexual dimorphism.

The purpose of this paper is to review the sexually dimorphic characters in the fossil record and how they might be interpreted in the context of our current understanding of primate socioecology.
\end{abstract}

\section{AUSTRALOPITHECUS AFARENSIS}

Size variation among individuals referred to as A. afarensis is striking (Aiello 1990, Aiello and Dean 1990, Frayer and Wolpoff 1985, Hartwig-Scherer 1993, Johanson et al. 1978, Johanson et al. 1982, Johanson and White 1979, Jungers 1988, Leutenegger 1982a, b, Leutenegger and Shell 1987, Lovejoy et al. 1989, McHenry 1982, 1983, 1986, 1988, 1991a, b, 1992a, b). Significant shape variation between the large and small individuals may be present as well (e.g. Senut 1978, 1980, 1986, Senut and Tardieu 1985, Stern and Susman 1983, Susman et al. 1984, Tardieu 1981, 1983, 1986, Zihlman 1985). Many have suggested that more than one species of hominid is represented in the Hadar and Laetoli collections from strata dated between 3.7 and 2.9 Myr (e.g. Coppens 1981, 1983, Falk 1986, Hartwig-Scherer 1993, Olson 1981, 1985, Schmid 1983, Senut and Tardieu 1985, Tuttle 1981, Zihlman 1985), but there is strong evidence that only one species is represented (e.g. Johanson and White 1979, Johanson et al. 1978, Kimbel 1984, 1986, Kimbel and White 1988b, Kimbel et al. 1982, McHenry 1983, 1991a, 1992a, White 1985, White et al. 1981).

If this sample is a single species, as a majority of scholars who work directly with the material maintain, then one estimate of the degree of body weight dimorphism based on hindlimb joint size is 1.5 (assuming a human-like relationship between hindlimb joint size and body weight as explained in McHenry 1991a, 1992a). Table 3.1 presents estimates of body weight for this and other species of early hominids. This degree of 
dimorphism is above modern H. sapiens (1.2) and species of Pan (1.4), but below Gorilla (2.1) and Pongo (2.0). Jungers (1988) and Lovejoy et al. (1989) find a similar degree of body size variation using different methods.

A palaeontological sample like that attributed to $A$. afarensis provides invaluable insights into the nature of hominids of the past, but is inevitably limited. All inferences must be built on the tenuous ground of current available evidence. The sample is small and spread over at least $0.5 \mathrm{Myr}$ and $800 \mathrm{~km}$ (i.e. Laetoli to Hadar). This means that the size variation observed within $A$. afarensis should not be expected to have a range like that of a modern species. But there are two palaeontological discoveries that are as close as one can expect to ever get to sampling the variability within a population of 3.7 to 2.9 Myr hominids: The $\mathrm{G}$ trails of Laetoli footprints and the sample in the A.L. 333 site of Hadar preserve records of body size variability within single populations. The $G$ trails were left by three individuals. The smallest footprints (G-1) correspond to an individual standing about $1.22 \mathrm{~m}$ tall and the largest (G-3) had a foot size matching a $1.41 \mathrm{~m}$ tall individual (Tuttle 1991). The body weights of individuals of these statures are $27.8 \mathrm{~kg}$ and $40.1 \mathrm{~kg}$ respectively (calculated from the power curve given in Jungers and Stern 1983). The ratio of large to small is 1.44 which is similar to the male/female ratio in Pan (1.4), above that in modern H. sapiens (1.2) and below that in Gorilla and Pongo (2.02.1). Unfortunately, one cannot know the age of maturity of the individuals; they may have been children or two children and a parent. Fortunately the 333 site of Hadar does contain the evidence needed to ascertain maturity. At least thirteen individuals appeared to have died at one time (Johanson et al. 1982, White and Johanson 1989). This number is based on the number of preserved jaws. The postcrania reveal the presence of at least three large adult individuals (represented by three left distal fibulae [A.L. 333-9B, -85, $-333 w-37]$ ) with fused epiphyses which are presumably males. Two adult small-bodied individuals (presumably females) are present as shown by two left tibia (A.L. 333-6 and 96). There are also one or more large sub-adults (A.L. 333w-33, $-333 \mathrm{w}-14 / 15$ and $-333-95)$. The range of size variation is well above that seen in any

Table 3.1 Body weight dimorphism in species of Hominoidea ${ }^{1}$ and fossil hominids ${ }^{2}$

\begin{tabular}{|c|c|c|c|}
\hline Species & Male & Female & Ratio \\
\hline A. afarensis & 44.6 & 29.3 & 1.5 \\
\hline A. africanus & 40.8 & 30.2 & 1.4 \\
\hline A. boisei & 48.6 & 34.0 & 1.4 \\
\hline A. robostus & 40.2 & 31.9 & 1.3 \\
\hline H. habilis sensu lato ${ }^{3}$ & 51.6 & 31.5 & 1.6 \\
\hline H. habilis sensu stricto ${ }^{3}$ & 37.0 & 31.5 & 1.2 \\
\hline H. rudolfensis ${ }^{3}$ & 59.6 & 50.8 & 1.2 \\
\hline early African $H$. erectus $(=H . \text { ergaster })^{3}$ & 62.7 & 52.3 & 1.2 \\
\hline Neanderthal ${ }^{4}$ & 60.1 & 51.8 & 1.2 \\
\hline
\end{tabular}


Early a.m. H. sapiens 4

70.0

64.9

H. sapiens

P. troglodytes

P. paniscus

G. gorilla

P. pygmaeus

H. syndactylus

H. lar
54.2

47.8

157.9

78.8

11.3

5.5
56.8

53.2

39.7

33.1

75.4

38.8

11.3

5.2

\section{Notes}

1 From McHenry (1991a).

2 From McHenry (1992a) except where indicated.

3 From McHenry (1994).

4 Derived from stature estimates in Feldesman et al. (1990) by regression formulae for male and female given in Table 11 of Ruff and Walker (1993). These body weights are probably underestimates of the true values, because these hominids were much more robust than the modern humans from whom the stature/weight formulae are derived. Adding $10 \mathrm{~kg}$ or even $20 \mathrm{~kg}$ does not appreciably affect the male/female ratio, however, since both sexes were robust.

modern human population. The largest hindlimb specimen, A.L. 333-3, corresponds to a modern human of about $50 \mathrm{~kg}$ and the smallest hindlimb specimen (A.L. 333-96) is as small as a $33.5 \mathrm{~kg}$ Pygmy.

The moderate level of body size variation is reflected in the jaws and teeth. This is significant because the sample sizes of jaws and teeth are much better. There are eleven mandibular and ten maxillary canines whose breadths can be measured reliably, and the variability (as measured by the coefficient of variation) is well below that of Gorilla, Pongo and Pan troglodytes, although lower canines in Pan paniscus are similar to A. afarensis in variability (Kimbel and White 1988a). The postcanine teeth do not exhibit unusually high degrees of variation (e.g. the CVs of their breadths are mostly below Gorilla and above H. sapiens; Kimbel and White 1988a). The robusticity of their mandibles is also not unusual (Kimbel and White 1988a).

There is much greater variation in forelimb size, however. The difference between large and small ulnae, radii and capitates is as great or greater than that between male and female means of the most dimorphic apes (McHenry 1986). If forelimb size is used to predict body weight, the result is a high level of variation that may imply very strong dimorphism or the existence of two species. Hartwig-Scherer (1993), for example, concludes that specimens referred to as A. afarensis may derive from more than one species because by her estimates, the degree of body weight sexual dimorphism based on both fore- and hindlimb size falls outside the range seen in modern species of hominoid. She predicts a female weight of approximately $30 \mathrm{~kg}$ which is similar to what most other authors have predicted, but a male weight of over $60 \mathrm{~kg}$. The latter is based on the midshaft circumferences of one radius (A.L. 333w-33, predicting a weight of $68 \mathrm{~kg}$ ) and one humerus (A.L. 333-107 predicting weights between 89 and $99 \mathrm{~kg}$ ). McHenry (1986) 
reports unexpectedly large forelimbs as well, especially the mediolateral diameter of the proximal ulna. The ratio between this measure in the largest specimen of $A$. afarensis (A.L. 333w-36) and the smallest (A.L. 33x-5) is greater than the ratio of male to female sizes in the most dimorphic great apes (Pongo and Gorilla). McHenry (1991a) notes that the smallest radial head (A.L. 288-1p) corresponds to a human weighing $28 \mathrm{~kg}$ and the largest (A.L. 333x-14/15) matches a $62 \mathrm{~kg} \mathrm{H}$. sapiens. The same pattern is apparent at Maka with an exceptionally large humerus (MAK-VP-1/3) and a small ulna (MAK-VP1/111; White et al. 1993) associated with A. afarensis at 3.4 Myr.

Why are forelimbs apparently more dimorphic than jaws, teeth or hindlimbs? There are at least four possible explanations. One explanation might be sampling bias (i.e. in the small sample of postcrania, smaller individuals are represented by hindlimbs and larger ones by forelimbs). While this is possible, the 333 site contains fore- and hindlimb specimens of both large and small morphs. If this is truly a simultaneous burial of a single group, then the big morph did have proportionately larger forelimbs than the small morph. A second explanation is that there are two species represented. Senut and Tardieu (1985) note, for example, that although the large distal humerus, A.L. 333w-29, is badly weathered, it appears to have a lateral epicondyle that projects more weakly and is in a lower position than is apparent in the smaller specimens (A.L. 137-48A, A.L. 288$1 \mathrm{M} \& S$, and A.L. 322-1) and the anterior lateral trochlear crest is only moderately developed in the large morph. My own observations of the original specimens do not confirm or deny these distinctions, because the key large specimen (A.L. 333w-29) is too badly abraded. Another problem with considering the two size morphs as two species is the fact they both occur at the 333 site.

A third possibility is that male $A$. afarensis had proportionately larger forelimbs than females because of selection for utilization of different ecological niches. From this point of view, males climbed more than females. This is just the opposite of the view so elegantly presented by Stern and Susman (1982). Related to this is the unlikely view that males differed from females because they needed large forelimbs to gather and carry more food to their less mobile female mates and offspring.

Finally, an explanation for larger forelimbs in males can be assessed from the point of view of sexual selection. Here one can invoke Darwin's words about canine reduction and remember that early hominids had free forelimbs.

The free use of the arms and hands, partly the cause and partly the result of man's erect position, appears to have led in an indirect manner to other modifications of structure. The early male forefathers of man were, as previously stated, probably furnished with great canine teeth; but as they gradually acquired the habit of using stones, clubs, or other weapons, for fighting with their enemies or rivals, they would use their jaws and teeth less and less. In this case, the jaws, together with the teeth, would become reduced in size, as we may feel almost sure from innumerable analogous cases.

(Darwin 1892:53) 


\section{AUSTRALOPITHECUS AFRICANUS}

Body size variability is also high in A. africanus (e.g. Aiello and Dean 1990, Feldesman and Lundy 1988, Geissmann 1986, Jungers 1988, McHenry 1974, 1975, 1976, 1988, 1991a, b, 1992a, b, Robinson 1972, Steudel 1980, Wolpoff 1973, 1975). Hindlimb jointsize predicts a male weight of $40.8 \mathrm{~kg}$ and female weight of $30.2 \mathrm{~kg}$ (McHenry 1992a). As in A. afarensis, there appears to be very strong dimorphism in forelimb size with some specimens (e.g. Stw 326, 390 and 418) corresponding in size to a $28 \mathrm{~kg}$ human Pygmy and others (e.g. Sts 7, Stw 113, 382 and 432) as large or larger than the equivalent elements in a $55 \mathrm{~kg}$ H. sapiens.

Dental and mandibular size dimorphism in A. africanus is similar to that seen in $A$. afarensis, although maxillary M2 breadths divide the thirty available specimens into two essentially non-overlapping groups (Kimbel and White 1988a). Facial and basicranial structure is exceptionally variable and may imply that two species are represented (Clarke 1988, Kimbel and Rak 1993, Kimbel and White 1988a). Variability in endocranial volume is quite low, however (Holloway 1970).

\section{AUSTRALOPITHECUS BOISEI}

The sample of postcrania of the hyper-robust hominid of East Africa is small because taxonomic attribution of isolated elements is difficult. Fortunately there is one partial associated skeleton found with a taxonomically diagnostic bit of jaw (KNM-ER 1500). There are a few specimens from a site (Arca 6A, Ileret) which has produced only $A$. boisei craniodental material. From these specimens the male is estimated to weigh 48.6 $\mathrm{kg}$ and the female $34 \mathrm{~kg}$, assuming human proportions (McHenry 1992a). These are very tenuous estimates because of the lack of material and the uncertainty about proportions and attributions. The ratio of male to female is 1.4 which is similar to that found in modern species of chimpanzee. Forelimbs may have been strongly dimorphic, but species attribution of isolated specimens precludes any certainty. The associated partial skeleton has small hindlimb joints corresponding to a $34 \mathrm{~kg}$ human, but its radial head is matched by a $50 \mathrm{~kg}$ human. There are several very large isolated forelimb fossils that may belong to the male $A$. boisei. For example, the KNM-ER 739 humerus has a distal end as large as what would be expected in a $72 \mathrm{~kg}$ male (McHenry 1992a) and its shaft circumference predicts a body weight of $79 \mathrm{~kg}$ (Hartwig-Scherer 1993).

Dental and mandibular variability in $A$. boisei is no greater than in earlier species of Australopithecus (Kimbel and White 1988a). The 'robust' features of the female face (KNM-ER 732) are less strongly developed than in the adult male (KNM-ER 406; Rak 1983). 


\section{AUSTRALOPITHECUS ROBUSTUS}

Body size dimorphism in the South African 'robust' australopithecine species appears to have been only moderate. The estimate for males is $40.2 \mathrm{~kg}$ and females $31.9 \mathrm{~kg}$, which yields a ratio of 1.26 which is similar to modern humans (McHenry 1992a). There is no evidence that male forelimbs were proportionately larger than those of females (McHenry 1991c). Variability in mandibular robusticity is below that seen in A. afarensis, A. africanus and species of African ape (Kimbel and White 1988a). Dental variability is also relatively moderate.

\section{EARLIEST HOMO (H. HABILIS AND RUDOLFENSIS)}

Two very different size morphs have been attributed to the earliest specie(s) of Homo. The small morph is represented by material from Olduvai Gorge such as the O.H. 8 partial foot (part of the paratype of Homo habilis), the tibia and fibula (O.H. 35) and the O.H. 62 partial skeleton. These specimens yield a body weight estimate of $31.5 \mathrm{~kg}$ (McHenry 1992a). The large morph is represented by specimens from Koobi Fora including the KNM-ER 1481 partial hindlimb, the KNM-ER 1472 femur, and the KNMER 3228 os coxa. A body weight of $51.6 \mathrm{~kg}$ is predicted from these fossils (McHenry 1992a). If these two morphs represent the male and female of $H$. habilis sensu lato, then their ratio is 1.6 (above modern chimps).

There is a growing concern, however, that two species are represented by these two morphs. Wood (1992) presents the most extensive work on this problem and concludes that the Olduvai early Homo is $H$. habilis and the large morph at Koobi Fora is $H$. rudolfensis. By this classification, some of the smaller specimens from Koobi Fora, such as the partial skeleton KNM-ER 3735 are H. habilis. Using Wood's (1992) classification, McHenry (1994) estimates the male H. habilis sensu stricto to be $37.0 \mathrm{~kg}$ and the female, $31.5 \mathrm{~kg}$ which yields a ratio of 1.2 (similar to modern humans). The estimate for the male H. rudolfensis is $62.7 \mathrm{~kg}$ and the female, $52.3 \mathrm{~kg}$, making a ratio of 1.2 (McHenry 1994).

Unfortunately, it is difficult to assess dimorphism in the earliest Homo because the taxonomy is still unresolved. Tobias (1991) presents a thorough review of $H$. habilis at Olduvai Gorge and concludes that the Koobi Fora early Homo can be accommodated into that species. Wood (1991) finds evidence for two species as do many others (e.g. Groves 1989, Kimbel and Rak 1993, Leakey and Leakey 1978, Lieberman et al. 1988, Rightmire 1993, Stringer 1986, Wood 1992, 1993). A major difficulty is that these and other authors often disagree on which specimens belong together in a single species and which do not. For example, the well preserved KNM-ER 1813 is H. habilis to Wood (1992), H. ergaster to Groves (1989) and Homo but not H. habilis to Stringer (1986) and Rightmire (1993). 


\section{EARLY AFRICAN HOMO ERECTUS}

The well preserved cranium, KNM-ER 3733, is usually attributed to $H$. erectus (e.g. Howell 1978, Leakey and Walker 1976, Rightmire 1990, Walker and Leakey 1978, Walker 1981,) and its early date, 1.8 Myr. (Fiebel et al. 1989), places it as the earliest of that species. The earliest postcranial fossils attributed to H. erectus are at $1.7 \mathrm{Myr}$ (Fiebel et al. 1989). As with pre-erectus Homo there is debate on specimen attribution and species name (e.g. Groves 1989, Kimbel and Rak 1993, Rightmire 1990, Wood 1991). Homo ergaster is often used for early specimens previously attributed to H. erectus (e.g. Groves 1989, Wood 1992).

Despite these disagreements about craniodental taxonomy, analysis of the postcranial remains is less problematical for early African H. erectus than it is for earlier Homo. This is due to the fact that there are several partial skeletons including the nearly complete specimen, KNM-WT 15000. Ruff and Walker (1993) give estimated body weights for many of these specimens. Assuming that the large specimens are male, a weight of 62.7 $\mathrm{kg}$ is appropriate for early H. erectus (McHenry 1994). The smaller specimens average $52.3 \mathrm{~kg}$ and may be close to the female average (McHenry 1994). The ratio is 1.2. The apparent dimorphism in relative forelimb size seen in earlier species is not present in $H$. erectus. The forelimbs of the male specimen, KNM-WT 15000, are relatively quite small. Unfortunately the sample is too small to make meaningful dental or mandibular comparisons in early African $H$. erectus, but in later members of that species (especially those from North Africa and Java) there appears to be quite strong sexual dimorphism in mandibular size (Frayer and Wolpoff 1985, Tyler 1991, Wolpoff 1980).

\section{NEANDERTHALS AND EARLY ANATOMICALLY MODERN HOMO SAPIENS}

Table 3.1 also presents estimates of body size in male and female Neanderthals and early anatomically modern Homo sapiens. These estimates are based on femoral length and its relationship to stature (Feldesman et al. 1990) and body weight (Ruff and Walker 1993). Like all estimates of body weight in fossil samples there is much room for error, but it is clear that the high level of body size dimorphism characteristic of early Australopithecus has disappeared. The degree of body weight dimorphism is about the same as modern $H$. sapiens (i.e. with a male/female ratio of 1.2), but interesting subtleties are present in the pattern of sexual dimorphism (Frayer 1980).

\section{SEXUAL SELECTION AND MATING SYSTEM}

What does the degree of dimorphism apparent in A. afarensis, A. africanus, and other species of early hominid imply about behaviour and ecology? It may be interpreted as indicating a polygynous mating system, but such a simple extrapolation needs considerable caution. 
In general, mammalian species with polygynous mating systems have a higher level of sexual dimorphism in body weight, canine size and other features than do species with monogamous mating systems (Alexander and Hoogland 1979, Clutton-Brock 1989, Clutton-Brock and Vincent 1991, Clutton-Brock et al. 1977, Frayer and Wolpoff 1985, Gaulin and Sailer 1984, Harvey and Bennett 1985, Harvey et al. 1978, Lande 1980, Leutenegger 1977, 1978, 1982a, b, Leutenegger and Kelly 1977, Plavcan and van Schaik 1992, Rodman and Mitani 1987, Willner and Martin 1985).

But can one predict mating system in extinct species? According to Rowell and Chism (1986:111) 'we do not think it is possible to infer the social systems or mating patterns of extinct species from the degree of sexual dimorphism shown by their fossils'. The problem is that there is a great deal of variability in the relationship between social system and degree of sexual dimorphism.

A general trend is clear: monogamous species have very low levels of body weight sexual dimorphism and polygynous species have higher dimorphism. Clutton-Brock et al. (1977) show this by comparing the socionomic index (number of adult females per male) with body weight ratio. The association holds up relatively well. Within the Order Primates, monogamous species are always monomorphic and polygynous species are usually dimorphic with males often weighing twice as much as females. Trivers (1972) explains how selection may drive the evolution of dimorphism in polygynous species. By this view male/male competition to monopolize the reproductive potential of females tends to favour greater size, strength, display and other sexually dimorphic characteristics among males. When the male impregnates a female, he monopolizes her reproductive potential for a long time and excludes other males. The potential exists for one male to impregnate several females, if he can exclude other males. Selection operates differently for the female, however, because of the vastly greater energetic cost of reproduction for the females (i.e. the energetics of gestation and lactation). Smaller females are not at the same disadvantage as small males in the competition for mates. In monogamous species, the difference disappears because the male cannot monopolize the reproductive potential of more than one female. Among primates, monomorphism is always associated with monogamous mating systems. The level of sexual dimorphism is not, however, closely associated with the degree of polygyny. Some polygynous species have high levels of dimorphism and some do not. The differences may have to do with the quality of male/male competition.

Plavcan and van Schaik (1992) fine tune the analysis by classifying four types of male/male competition and its relationship with canine dimorphism. Type 1 by their analysis (low-frequency and low-intensity competition) includes monogamous primates such as Hylobates, Callicebus and Saguinus. Type 2 is high-frequency, low-intensity inter-male competition and includes Pan, Ateles, Lagothrix and Pithecia, although there is little known about the social behaviour of the latter two. Type 3 is low-frequency, high-intensity and type 4 is high-frequency, high-intensity. Calculating the male/female ratio of body weight in these categories (correcting for taxonomic artefact following Pagel and Harvey 1988) leads to the following: competition type 1 has a male/female body weight ratio of 1.01; type 2 has 1.18 ; type 3 has 1.55 ; and type 4 has 1.51 .

These results show (1) that there is a striking relationship between the intensity of male/male competition and the degree of sexual dimorphism in canine and body size and 
(2) that there is a clear difference in body weight dimorphism between species of low and high frequency of inter-male competition, among the species with low intensity competition. The degree of body size sexual dimorphism in early hominids fits well within competition type 2 (high-frequency, low-intensity like Pan and Ateles).

But even with fine-tuning, the relationship between sexual dimorphism and social behaviour is not simple. Among primates, several groups provide challenges. Species of the suborder Anthropoidea hold fairly well to the rule of monogamy/monomorphism and polygyny/sexual dimorphism. Exceptions appear (e.g. Cercopithecus neglectus is sexually dimorphic in body size but early reports gave its mating system as monogamous), but further information substantiates the generalization ( $C$. neglectus is polygynous, Leutenegger and Lubach 1987, Wahome et al. 1993). Prosimians are another matter altogether.

Mating systems among Prosimii range from strict monogamy to polygyny with multimale/multi-female groups. Size varies from $60 \mathrm{~g}$ to $10 \mathrm{~kg}$ in living Malagasy lemurs and up to $150 \mathrm{~kg}$ in the subfossil, Megaladapis (Fleagle 1988, Godfrey et al. 1993). But there is no sexual dimorphism in body size (Godfrey et al. 1993, Richard 1992). Several explanations for this are possible (reviewed in Godfrey et al. 1993 and Richard 1992). Godfrey et al. (1993:331) suggest that 'hypometabolism and intersexual resource competition during a critical period in the reproductive cycle of females may have constrained the evolution of sexual size dimorphism in Malagasy lemurs'.

\section{OTHER CORRELATES TO DIMORPHISM}

Although sexual selection appears to be an important cause of sexual dimorphism in anthropoid primates, other factors may be involved. Oxnard (1983) stresses the need to understand the multifactorial causes of dimorphism. Body size itself explains much of the variance in sexual dimorphism according to Leutenegger (1982a, b) and Leutenegger and Cheverud (1982, 1985), although body size has only a minor effect according to other studies (Gaulin and Sailer 1984, Plavcan and van Schaik 1992). Predation pressure may be important (Harvey et al. 1978, Rowell and Chism 1986). Phylogenetic inertia has been emphasized particularly by Cheverud et al. (1985, 1986), but Ely and Kurland (1989) challenge this view. Dietary constraints may be important (Demment 1983, Milton 1985). The dispersion of food sources, mobility of males and philopatry may be related to reduced dimorphism in chimpanzees (Rodman 1984). Economic and non-economic role differences which result in the division of labour by sex may be important in explaining sexual dimorphism in many primates, especially hominids (Frayer and Wolpoff 1985).

\section{BEHAVIOURAL AND ECOLOGICAL CORRELATES OF DIMORPHISM IN EARLY HOMINIDS}

Although the relationship between body size sexual dimorphism and mating system is not exact in anthropoid primates, the degree of dimorphism apparent in A. afarensis and $A$. africanus makes it unlikely that these species were monogamous (contra Lovejoy 1981, 
1988). It is likely, although less certain, that male/male competition was less intense than that seen in the highly dimorphic primates such as Gorilla and Pongo. While it is possible that these species lived in groups comprising a single breeding male and several adult females with dependent offspring (i.e. like Gorilla), patrilineal, multi-male groups seem more likely (Foley and Lee 1989). If it is true that the 333 site of Hadar samples a single population at one point in time, then the group composition was multi-male/ multifemale. If they did live in kin-related, multi-male groups, it is odd that their descendants have relative low testes weights unlike one of our close biological relatives, chimpanzees (Harcourt et al. 1981). Perhaps the testes size of modern humans is not what it used to be.

Although taxonomic uncertainty obscures a clear picture of sexual dimorphism in $H$. habilis sensu lato, by 1.7 Myr the degree of body size and forelimb size dimorphism in Homo erectus is substantially reduced from that seen in its ancestors. Small-bodied hominids all but disappear from the East African fossil record at $1.7 \mathrm{Myr}$ and the body size within early $H$. erectus is similar to that seen in modern $H$. sapiens. This change was due to an increase in both female and male body size by as much as $22 \mathrm{~kg}$ from that seen in Australopithecus. The effect of this equal increase in the two sexes results in a reduced ratio.

What behavioural and/or ecological factors might be correlated with the dramatic change in body weight sexual dimorphism that occurred with the appearance of $H$. erectus? Certainly it is not related to species body size change, because it reverses the trend (i.e. H. erectus is larger than A. afarensis and A. africanus but has a lower level of sexual dimorphism). Nor can phylogenetic inertia be invoked because of the ancestordescendant relationship between $A$. afarensis-A. africanus-early Homo (Skelton and McHenry 1992). Reduced intensity of male/male competition might be involved and may explain the reduced forelimb size dimorphism, but the reduced body size dimorphism seen in $H$. erectus is due to both male and female body size increase and not to a reduction in male body size.

Perhaps the relaxation of dietary constraints is related to the change in body weight dimorphism apparent in $H$. erectus. It appears that $H$. erectus was less restricted in habitat usage than was Australopithecus (Shipman and Harris 1988) and may have incorporated more animal products (meat and/or marrow) into the diet (Potts 1988). The larger body size and especially longer hindlimbs of $H$. erectus would allow greater travel distances between more widely distributed food sites. Another possible explanation for increased body weight is related to increased frequency and intensity of interdemic conflict. In this case selection favoured larger-bodied individuals and their close kin who were successful in aggressive encounters with conspecifics. Related to this could be the appearance of the Acheulian handaxe and its use as a projectile.

More difficult to explain is the proportionately greater increase in size of the H. erectus female. The male $H$. erectus is about 50 per cent larger than his Australopithecus ancestors, but the female is more than 70 per cent larger. Perhaps the greater increase in female body size was due to selection for physiological mechanisms to produce larger brains. The expected neonatal brain size predicted from the female body weight of $A$. africanus is $166 \mathrm{~g}$ and for early $H$. erectus, $270 \mathrm{~g}$ (McHenry 1994). This would probably have been related to a change in diet. Another explanation for the reduced male/female body weight ratio in $H$. erectus might be related to biomechanical restraints on maximum 
body size. Males who exceeded $60-70 \mathrm{~kg}$ were selected against because of physical failures such as back injuries that continue to plague this bipedal animal. In this regard it is interesting to note that KNM-WT 15000 had relatively small lumbar vertebrae (in cross-sectional area) unlike the augmented size of modern humans of equivalent body weight (Latimer and Ward 1993).

\section{CONCLUSIONS}

Body weight sexual dimorphism in A. afarensis is above that seen in modern humans and chimps, but well below that characteristic of gorillas and orangs. As in other animals, sexual selection probably accounts for this dimorphism and is most likely related to a polygynous mating system. The level of body weight dimorphism in A. afarensis corresponds to what might be expected from moderate intensity male/male competition. Kin-related multi-male groups are most likely based on the composition of the A.L. 333 site at Hadar and on theoretical considerations.

Canine dimorphism in A. afarensis is well below that seen in the great apes (except for the lower canines in Pan paniscus), but forelimb size dimorphism is apparent. This may be related to the fact that forelimbs were freed from any role in terrestrial locomotion and thereby took over the role of threat and aggression previously played by the canines.

Body weight dimorphism declines through time from $A$. afarensis to $A$. africanus to $A$. robustus with a dramatic reduction in $H$. erectus. Taxonomic attributions of specimens formerly assigned to $H$. habilis obscure the analysis of dimorphism in pre-erectus Homo, unfortunately.

The dramatic reduction in body weight sexual dimorphism at $1.7 \mathrm{Myr}$ with the appearance of $H$. erectus is due to increase in both male and female body size. The cause of this change is probably related to the release of dietary constraints on body size, selection for larger brains and biomechanical constraints on maximum male body size. It may also be due to reduced male/male competition.

Sexual dimorphism is very high in some traits such as mandibular size in later $H$. erectus, but there are too few postcranial remains of later $H$. erectus and early $H$. sapiens to assess body weight dimorphism. Weight dimorphism in Neanderthals and early anatomically modern $H$. sapiens is as low as that seen in modern humans.

\section{ACKNOWLEDGEMENTS}

The author thanks R.E.Leakey and M.G.Leakey and the staff of the National Museums of Kenya, M.D.Leakey, F.C.Howell, D.C.Johanson and the staff of the Cleveland Museum of Natural History and the Institute of Human Origins, Tadessa Terfa, Mammo Tessema, Berhane Asfaw and the staff of the National Museum of Ethiopia, C.K.Brain and the staff of the Transvaal Museum, P.V.Tobias and the staff of the Department of Anatomy and Human Biology, University of Witwatersrand, for permission to study the original fossil material in their charge and for numerous kindnesses. The author also thanks D.R. Howlett, C.Powell-Cotton and staff of the Powell-Cotton Museum; M. Rutzmoser and 
staff of the Museum of Comparative Zoology, Harvard University; R.Thorington and the staff of the Division of Mammalogy, Smithsonian Institution; D.J.Ortner and the staff of the Department of Anthropology, Smithsonian Institution; D.F.E.T. van den Audenaerde and M.Lovette and the staff of the Musée d'Afrique Centrale, Tervuren; R.D. Martin and the staff of the Anthropologische Institut, Zurich; W.W. Howells and the staff of the Peabody Museum, Harvard University; C. Edelstamm and the staff of the Natur Historiska Rismuseet, Stockholm; R.L.Susman and W.L.Jungers for many kindnesses and for permission to study the comparative material in their charge; L.J.McHenry, L.Digby, A.H.Harcourt, and P.S.Rodman for insightful comments on early drafts. J.Martini for her help in preparing this paper; and Stephen Shennan and James Steele for inviting me to participate in this symposium. Partial funding was provided by the Committee of Research, University of California, Davis.

\section{REFERENCES}

Aiello, L.C. (1990) 'Patterns of stature and weight in human evolution.' American Journal of Physical Anthropology 81:186-187.

Aiello, L. and Dean, C. (1990) An Introduction to Human Evolutionary Anatomy. London: Academic Press (Harcourt Brace Jovanovich).

Alexander, R.D. and Hoogland, J.L. (1979) 'Sexual dimorphisms and breeding systems in pinnipeds, ungulates, primates, and humans.' In N.A.Chagnon and W.Irons (eds) Evolutionary Biology and Human Social Behavior, pp. 402-435. North Scituate: Duxbury Press.

Cheverud, J.M., Low, M.M. and Leutenegger, W. (1985) 'The quantitative assessment of phylogenetic constraints in comparative analysis - sexual dimorphism in body weight among primates.' Evolution 39:1335-1351.

Cheverud, J.M., Low, M.M. and Leutenegger, W. (1986) 'A phylogenetic autocorrelation analysis of sexual dimorphism in primates.' American Anthropologist 88:916-922.

Clarke, R.J. (1988) 'A new Australopithecus cranium from Sterkfontein and its bearing on the ancestry of Paranthropus.' In F.E.Grine (ed.) Evolutionary History of the 'Robust' Australopithecines, pp. 285-292. New York: Aldine de Gruyter.

Clutton-Brock, T.H. (1989) 'Mammalian mating systems.' Proceedings of the Royal Society of London B 236:339-372.

Clutton-Brock, T.H. and Vincent, A.C.J. (1991) 'Sexual selection and the potential reproductive rates of males and females.' Nature 351:58-60.

Clutton-Brock, T.H., Harvey, P.H. and Rudder, B. (1977) 'Sexual dimorphism, socionomic sex ratio and body weight in primates.' Nature 269:797-800.

Coppens, Y. (1981) 'Le cerveau des hommes fossiles.' Comptes Rendues de l'Academie des Sciences, Paris: Supplément à la vie académique 3-24.

Coppens, Y. (1983) 'Systematics, phylogeny, environment and culture of the Australopithecines, hypothesis and synthesis.' Bulletin et Mémoires de la Société d'Anthropologie de Paris 13:273-284.

Darwin, C. (1892) The Descent of Man, and Selection in Relation to Sex, new edition. New York: D.Appleton and Company.

Demment, M.W. (1983) 'Feeding ecology and the evolution of body size of baboons.' African Journal of Ecology 21:219-233. 
Ely, J. and Kurland, J.A. (1989) 'Spatial autocorrelation, phylogenetic constraints, and the causes of sexual dimorphism in primates.' International Journal of Primatology 10:151-171.

Falk, D. (1986) 'Evolution of cranial blood drainage in hominids: enlarged occipital/marginal sinuses and emissary foramina.' American Journal of Physical Anthropology 70:311-324.

Feldesman, M.R. and Lundy, J.K. (1988) 'Stature estimates for some African PliocenePleistocene fossil hominids.' Journal of Human Evolution 17: 583-596.

Feldesman, M.R., Kleckner, J.G. and Lundy, J.K. (1990) 'Femur/stature ratio and estimates of stature in Mid- and Late-Pleistocene fossil hominids.' American Journal of Physical Anthropology 83:359-372.

Fiebel, C.S., Brown, F.H. and McDougall, I. (1989) 'Stratigraphic context of fossil hominids from the Omo Group Deposits: Northern Turkana Basin.' American Journal of Physical Anthropology 78:595-622.

Fleagle, J.G. (1988) Primate Adaptation and Evolution. New York: Academic Press.

Foley, R.A. and Lee, P.C. (1989) 'Finite social space, evolutionary pathways, and reconstructing hominid behavior.' Science 243:901-906.

Frayer, D.W. (1980) 'Sexual dimorphism and cultural evolution in the Late Pleistocene and Holocene of Europe.' Journal of Human Evolution 9: 399-415.

Frayer, D.W. and Wolpoff, M.H. (1985) 'Sexual dimorphism.' Annual Review of Anthropology 14:429-474.

Gaulin, S.J.C. and Sailer, L.D. (1984) 'Sexual dimorphism in weight among the primates: the relative impact of allometry and sexual selection.' International Journal of Primatology 5:515-535.

Geissmann, T. (1986) 'Estimation of Australopithecine stature from long bones: A.L.288-1 as a test case.' Folia Primatologica 47:119-127.

Godfrey, L.R., Lyon, S.K. and Sutherland, M.R. (1993) 'Sexual dimorphism in largebodied primates: the case of the subfossil lemurs.' American Journal of Physical Anthropology 90:315-334.

Groves, C.P. (1989) A Theory of Human and Primate Evolution. Oxford: Clarendon Press.

Harcourt, A.H., Harvey, P.H., Larson, S.G. and Short, R.V. (1981) 'Testis weight, body weight, and breeding system in primates.' Nature 293:55-57.

Hartwig-Scherer, S. (1993) 'Body weight prediction in early fossil hominids: towards a Taxon-“Indepedent” approach.' American Journal of Physical Anthropology 92:17-36.

Harvey, P.H. and Bennett, P.M. (1985) 'Sexual dimorphism and reproduction strategies.' In J.Ghesquiere, R.D.Martin and F.Newcombe (eds) Human Sexual Dimorphism, pp. 43-59. London: Taylor and Francis.

Harvey, P.H., Clutton-Brock, T.H. and Kavanagh, M. (1978) 'Sexual dimorphism in primate teeth.' Journal of Zoology, London 186:475-485.

Holloway, R.L. (1970) 'New endocranial values for the Australopithecines.' Nature 227:199-200.

Howell, F.C. (1978) 'Hominidae.' In V.J.Maglio and H.B.S.Cooke (eds) The Evolution of African Mammals, pp. 154-248. Cambridge, MA: Harvard University Press.

Johanson, D.C. and White, T.D. (1979) 'A systematic assessment of early African hominids.' Science 203:321-330.

Johanson, D.C., White, T.D. and Coppens, Y. (1978) 'A new species of the genus Australopithecus (Primates: Hominidae) from the Pliocene of Eastern Africa.' Kirtlandia 28:1-14. 
Johanson, D.C., Taieb, M. and Coppens, Y. (1982) 'Pliocene hominids from the Hadar Formation, Ethiopia (1973-1977): stratigraphic, chronologic, and paleoenvironmental contexts, with notes on hominid morphology and systematics.' American Journal of Physical Anthropology 57:373-402.

Jungers, W.L. (1988) 'New estimations of body size in australopithecines.' In F.E.Grine (ed.) Evolutionary History of the 'Robust' Australopithecines, pp. 115-126. New York: Aldine de Gruyter.

Jungers, W.L. and Stern, J.T. (1983) 'Body proportions, skeletal allometry and locomotion in the Hadar hominids: a reply to Wolpoff.' Journal of Human Evolution 12:673-684.

Kimbel, W.H. (1984) 'Variation in the pattern of cranial venous sinuses and hominid phylogeny.' American Journal of Physical Anthropology 63:243-264.

Kimbel, W.H. (1986) 'Calvarial morphology of Australopithecus afarensis: a comparative phylogenetic study.' Dissertation, Kent State University.

Kimbel, W.H. and Rak, Y. (1993) 'The importance of species taxa in paleoanthropology and an argument for the phylogenetic concept of the species category.' In W.H.Kimbel and L.B.Martin (eds) Species, Species Concepts, and Primate Evolution, pp. 461-483. New York: Plenum Press.

Kimbel, W.H. and White, T.D. (1988a) 'Variation, sexual dimorphism and the taxonomy of Australopithecus' In F.E.Grine (ed.) Evolutionary History of the 'Robust' Australopithecines, pp. 175-192. New York: Aldine de Gruyter.

Kimbel, W.H. and White, T.D. (1988b) 'A revised reconstruction of the adult skull of Australopithecus afarensis.' Journal of Human Evolution 17:545-550.

Kimbel, W.H., Johanson, D.C. and Coppens, Y. (1982) 'Pliocene hominid cranial remains from the Hadar Formation, Ethiopia.' American Journal of Physical Anthropology 57:453-500.

Lande, R. (1980) 'Sexual dimorphism, sexual selection and adaptation in polygenic characters.' Evolution 34:292-305.

Latimer, B. and Ward, C.V. (1993) 'The thoracic and lumbar vertebrae.' In A. Walker and R.Leakey (eds) The Nariokotome Homo erectus Skeleton, pp. 266-293. Cambridge, MA: Harvard University Press.

Leakey, R.E.F. and Leakey, M.G. (1978) The Fossil Hominids and an Introduction to their Context 1967-1974. Koobi Fora Research Project, 1. Oxford: Clarendon Press.

Leakey, R.E.F. and Walker, A.C. (1976) 'Australopithecus, Homo erectus and the single species hypothesis.' Nature 261:572-574.

Leutenegger, W. (1977) 'Sociobiological correlates of sexual dimorphism in body weight in South African Australopiths.' South African Journal of Science 73: 143-144.

Leutenegger, W. (1978) 'Scaling of sexual dimorphism in body size and breeding system in primates.' Nature 272:610-611.

Leutenegger, W. (1982a) 'Scaling of sexual dimorphism in body weight and canine size in primates.' Folia Primatologica 37:163-176.

Leutenegger, W. (1982b) 'Sexual dimorphism in nonhuman primates.' In R.L. Hall (ed.) Sexual Dimorphism in Homo sapiens, pp. 11-36. New York: Praeger.

Leutenegger, W. and Cheverud, J. (1982) 'Correlates of sexual dimorphism in primates: ecological and size variables.' International Journal of Primatology 3: 387-402.

Leutenegger, W. and Cheverud, J.M (1985) 'Sexual dimorphism in primates: the effects of size.' In W.L.Jungers (ed.) Size and Scaling in Primate Biology, pp. 33-50. New York: Plenum Press.

Leutenegger, W. and Kelly, J.T. (1977) 'Relationship of sexual dimorphism in canine 
size and body size to social, behavioral, and ecological correlates in anthropoid primates.' Primates 18:117-136.

Leutenegger, W. and Lubach, G. (1987) 'Sexual dimorphism, mating system, and effect of phylogeny in De Brazza's monkey (Cercopithecus neglectus).' American Journal of Primatology 13:171-179.

Leutenegger, W. and Shell, B. (1987) 'Variability and sexual dimorphism in canine size of Australopithecus and extant hominoids.' Journal of Human Evolution 16:359-368.

Lieberman, D.E., Pilbeam, D.R. and Wood, B.A. (1988) 'A probabilistic approach to the problem of sexual dimorphism in Homo habilis: a comparison of KNM-ER 1470 and KNM-ER 1813.' Journal of Human Evolution 17:503-512.

Lovejoy, C.O. (1981) 'The origin of man.' Science 211:341-350.

Lovejoy, C.O. (1988) 'Evolution of human walking.' Scientific American November: $118-126$.

Lovejoy, C.O., Kern, K.F., Simpson, S.W. and Meindl, R.S. (1989) 'A new method for estimation of skeletal dimorphism in fossil samples with an application to Australopithecus afarensis.' In G.Giacobini (ed.) Hominidae: Proceedings of the 2nd International Congress of Human Paleontology Turin, September 28-October 3 1987, pp. 103-108. Milan: Jaka.

McHenry, H.M. (1974) 'How large were the Australopithecines?' American Journal of Physical Anthropology 40:329-340.

McHenry, H.M. (1975) 'Fossil hominid body weight and brain size.' Nature 254: 686688.

McHenry, H.M. (1976) 'Early hominid body weight and encephalization.' American Journal of Physical Anthropology 45:77-84.

McHenry, H.M. (1982) 'The pattern of human evolution: studies on bipedalism, mastication and encephalization.' Annual Review of Anthropology 11:151-173.

McHenry, H.M. (1983) 'The capitate of Australopithecus afarensis and Australopithecus africanus.' American Journal of Physical Anthropology 62:187-198.

McHenry, H.M. (1986) 'Size variation in the postcranium of Australopithecus afarensis and extant species of Hominoidea.' Journal of Human Evolution 15:149-156.

McHenry, H.M. (1988) 'New estimates of body weights in early hominids and their significance to encephalization and megadontia in "robust" australopithecines.' In F.E.Grine (ed.) Evolutionary History of the 'Robust' Australopithecines, pp. 133-148. New York: Aldine de Gruyter.

McHenry, H.M. (1991a) 'Sexual dimorphism in Australopithecus afarensis.' Journal of Human Evolution 20:21-32.

McHenry, H.M. (1991b) 'Femoral lengths and stature in Plio-Pleistocene hominids.' American Journal of Physical Anthropology 85:149-158.

McHenry, H.M. (1991c) 'Petite bodies of the "robust" australopithecines.' American Journal of Physical Anthropology 86:445-454.

McHenry, H.M. (1992a) 'Body size and proportions in early hominids.' American Journal of Physical Anthropology 87:407-431.

McHenry, H.M. (1992b) 'How big were early hominids?' Evolutionary Anthropology $1: 15-19$.

McHenry, H.M. (1994) 'Behavioral ecological implications of early hominid body size.' Journal of Human Evolution 27:77-87.

Milton, K. (1985) 'Multi-male mating and absence of canine tooth dimorphism in woolly spider monkeys (Brachyteles arachnoides).' American Journal of Physical Anthropology 68:519-524. 
Olson, T.R. (1981) 'Basicranial morphology of the extant hominoids and Pliocene hominoids: the new material from the Hadar Formation, Ethiopia, and its significance in early human evolution and taxonomy.' In C.B.Stringer (ed.) Aspects of Human Evolution, pp. 99-128. London: Taylor and Francis.

Olson, T.R. (1985) 'Cranial morphology and systematics of the Hadar formation hominids and “Australopithecus" africanus' In E.Delson (ed.) Ancestors: The Hard Evidence, pp. 102-119. New York: Alan R.Liss, Inc.

Oxnard, C.E. (1983) 'Anatomical, biomolecular and morphometric views of the primates.' In V.Navaratnam and R.J.Harrison (eds) Progress in Anatomy, 3, pp. 113142. Cambridge: Cambridge University Press.

Pagel, M.D. and Harvey, P.H. (1988) 'The taxon-level problem in the evolution of mammalian brain size: facts and artifacts.' American Naturalist 132:344-359.

Plavcan, J.M. and van Schaik, C.P. (1992) 'Intrasexual competition and canine dimorphism in anthropoid primates.' American Journal of Physical Anthropology 87:461-477.

Potts, R. (1988) Early Hominid Activities at Olduvai. New York: Aldine de Gruyter.

Rak, Y. (1983) The Australopithecine Face. New York: Academic Press.

Richard, A.F. (1992) 'Aggressive competition between males, female-controlled polygyny and sexual monomorphism in a Malagasy primate, Propithecus verreauxi.' Journal of Human Evolution 22:395-406.

Rightmire, G.P. (1990) The Evolution of Homo Erectus. Cambridge: Cambridge University Press.

Rightmire, G.P. (1993) 'Variation among early Homo crania from Olduvai Gorge and the Koobi Fora region.’ American Journal of Physical Anthropology 90:1-33.

Robinson, J.T. (1972) Early Hominid Posture and Locomotion. Chicago, IL: University of Chicago Press.

Rodman, P.S. (1984) 'Foraging and social systems of orangutans and chimpanzees.' In P.S.Rodman and J.G.H.Cant (eds) Adaptations for Foraging in Nonhuman Primates, pp. 136-159. New York: Columbia University Press.

Rodman, P.S. and Mitani, J.C. (1987) 'Orangutans: sexual dimorphism in a solitary species.' In B.B.Smuts, D.L.Cheney, R.M.Seyfarth, R.W. Wrangham and T.T.Struhsaker (eds) Primate Societies, pp. 146-154. Chicago: University of Chicago Press.

Rowell, T.E. and Chism, J. (1986) 'Sexual dimorphism and mating systems: jumping to conclusions.' In M.Pickford and B.Chiarelli (eds) Sexual Dimorphism in Living and Fossil Primates, pp. 107-111. II Sedicesimo: Giugno.

Ruff, C.B. and Walker, A. (1993) 'Body size and body shape.' In A.Walker and R.Leakey (eds) The Nariokotome Homo erectus Skeleton, pp. 234-265. Cambridge, MA: Harvard University Press.

Schmid, P. (1983) 'Eine Rekonstruktion des skelettes von A.L. 288-1 (Hadar) und deren Konsequenzen.’ Folia Primatologica 40:283-306.

Senut, B. (1978) 'Revision de quelques pièces humerales Plio-Pleistocene Sud-

Africaines.' Bulletins et Mémoires de la Société d'Anthropologie de Paris 5: 223-229.

Senut, B. (1980) 'New data on the humerus and its joints in Plio-Pleistocene hominoids.' Collection Anthropologie 4:87-93.

Senut, B. (1986) 'Long bones of the primate upper limb: monomorphic or dimorphic?' Human Evolution 1:7-22.

Senut, B. and Tardieu, C. (1985) 'Functional aspects of Plio-Pleistocene hominoid limb bones: implications for taxonomy and phylogeny.' In E.Delson (ed.) Ancestors: The 
Hard Evidence, pp. 193-201. New York: Alan R.Liss, Inc.

Shipman, P. and Harris, J. (1988) 'Habitat preference and paleoecology of Australopithecus boisei in eastern Africa.' In F.E.Grine (ed.) Evolutionary History of the 'Robust' Australopithecines, pp. 343-382. New York: Aldine de Gruyter.

Skelton, R.R. and McHenry, H.M. (1992) 'Evolutionary relationships among early hominids.' Journal of Human Evolution 23:309-349.

Stern, J.T. and Susman, R.L. (1983) 'The locomotor anatomy of Australopithecus afarensis' American Journal of Physical Anthropology 60:279-318.

Steudel, K. (1980) 'New estimates of early hominid body size.' American Journal of Physical Anthropology 52:63-70.

Stringer, C.B. (1986) 'The credibility of Homo habilis.' In B.Wood, L.Martin and P.Andrews (eds) Major Topics in Primate and Human Evolution, pp. 266-294. Cambridge: Cambridge University Press.

Susman, R.L., Stern, J.T. and Jungers, W.L. (1984) 'Arboreality and bipedality in the Hadar hominids.' Folia Primatologica 43:113-156.

Tardieu, C. (1981) 'Morphofunctional analysis of the articular surfaces of the knee-joint in primates.' In A.B.Chiarelli and R.S.Corruccini (eds) Primate Evolutionary Biology, pp. 68-80. Berlin: Springer-Verlag.

Tardieu, C. (1983) L'articulation du genou. Analyse morpho-fonctionelle chez les primates et les hominides fossiles. Paris: Cahiers de Paléoanthropologie. Editions du CNRS.

Tardieu, C. (1986) 'The knee joint in three hominoid primates: application to PlioPleistocene hominids and evolutionary implications.' In D.M.Taub and F.A.King (eds) Current Perspectives in Primate Biology, pp. 182-192. New York: Van Nostrand Reinhold.

Tobias, P.V. (1991) Olduvai Gorge Volume 4: The Skulls, Endocasts and Teeth of Homo habilis. Cambridge: Cambridge University Press.

Trivers, R.L. (1972) 'Parental investment and sexual selection.' In B.Campbell (ed.) Sexual Selection and the Descent of Man, pp. 136-179. Chicago: Aldine.

Tuttle, R.H. (1981) 'Evolution of hominid bipedalism and prehensile capabilities.' Philosophical Transactions of the Royal Society of London B 292: 89-94.

Tuttle, R.H. (1991) 'Laetoli toes and Australopithecus afarensis.' Human Evolution 6:193-200.

Tyler, D.E. (1991) 'A taxonomy of Javan hominid mandibles.' Human Evolution 6:401420.

Wahome, J.M., Rowell, T.E. and Tsingalia, H.M. (1993) 'The natural history of de Brazza's monkey in Kenya.' International Journal of Primatology 14: 445-466.

Walker, A. (1981) 'The Koobi Fora hominids and their bearing on the origins of the genus Homo.' In B.A.Sigmon and J.S.Cybulski (eds) Homo erectus, pp. 193-215. Toronto: University of Toronto Press.

Walker, A. and Leakey, R.E.F. (1978) 'The hominids of East Turkana.' Scientific American 239:54-66.

White, T.D. (1985) 'The hominids of Hadar and Laetoli: an element-by-element comparison of the dental samples.' In E.Delson (ed.) Ancestors: The Hard Evidence, pp. 138-152. New York: Alan R.Liss, Inc.

White, T.D. and Johanson, D.C. (1989) 'The hominid composition of Afar locality 333: some preliminary observations.' In G.Giacobini (ed.) Hominidae: Proceedings of the 2nd International Congress of Human Paleontology Turin, September 28-October 3 1987, pp. 97-102. Milan: Jaka. 
White, T.D., Johanson, D.C. and Kimbel, W.H. (1981) 'Australopithecus africanus: its phylogenetic position reconsidered.' South African Journal of Science 77: 445-470.

White, T.D., Suwa, G., Hart, W.K., Walter, R.C., WoldeGabriel, G., de Heinzelin, J., Clark, J.D., Asfaw, B. and Vrba, E. (1993) 'New discoveries of Australopithecus at Maka in Ethiopia.' Nature 366:261-265.

Willner, L.A. and Martin, R.D. (1985) 'Some basic principles of mammalian sexual dimorphism.’ In L.J.Ghesquiere, R.D.Martin and F.Newcombe (ed.) Human Sexual Dimorphism. London: Taylor and Francis.

Wolpoff, M.H. (1973) 'Posterior tooth size, body size, and diet in South African gracile australopithecines.' American Journal of Physical Anthropology 39:375-394.

Wolpoff, M.H. (1975) 'Sexual dimorphism in the Australopithecines.' In R.H. Tuttle (ed.) Paleoanthropology, Morphology and Paleoecology, pp. 245-284. The Hague: Mouton.

Wolpoff, M.H. (1980) 'Cranial remains of Middle Pleistocene European hominids.' Journal of Human Evolution 9:339-358.

Wood, B.A. (1991) Koobi Fora Research Project IV: Hominid Cranial Remains From Koobi Fora. Oxford: Clarendon.

Wood, B.A. (1992) 'Origin and evolution of the genus Homo.' Nature 355: 783-790.

Wood, B. (1993) 'Early Homo: How many species?' In W.H.Kimbel and L.B. Martin (eds) Species, Species Concepts, and Primate Evolution, pp. 485-522. New York: Plenum Press.

Zihlman, A. (1985) 'Australopithecus afarensis: two sexes or two species?' In P.V. Tobias (ed.) Hominid Evolution: Past, Present and Future, pp. 213-220. New York: Alan R.Liss, Inc. 